\title{
Inmigrantes en territorios de frontera. La ciudad de los otros. Santiago de Chile
}

Francisca Márquez. Universidad Alberto Hurtado, Santiago, Chile.

RESUMEN | En este artículo se aborda la construcción y génesis de territorios de frontera por parte de inmigrantes en Santiago de Chile, específicamente en La Chimba, al norte del río Mapocho. Se analiza este habitar de frontera desde evidencias de la historia, la sociología, georreferenciación y etnografía. La tesis central dice que el habitar de frontera se crea y se transforma en fuente de poder y ejercicio ciudadano, cuando la configuración de los territorios que cobijan a los inmigrantes es capaz de alimentar y ensanchar el campo de lo posible, más allá de la sobrevivencia. Se concluye que en La Chimba, la realización de la vita activa en los migrantes se levanta sobre una paradoja: cobijo y arraigo (condición de comunidad y redes de protección); itinerancia y movimiento (condición de translocalidad y conectividad). Esta paradoja resguarda la identidad de los habitantes en la multiculturalidad, pero a su vez abre la conectividad más allá de las fronteras del barrio, de la ciudad y la nación.

PALABRAS CLAVE | cultura urbana, imaginarios urbanos, migración.

ABSTRACT | The article deals with the genesis and building of frontier territories by immigrants Santiago de Chile, specifically in La Chimba, north of the Mapocho River. The settling of this frontier territory is analyzed based on historical, sociological, georeferencing and ethnographic evidence. The central thesis suggests that frontier living is created and becomes a source of empowerment and citizenship when the conformation of the spaces that are host to the immigrants and provide them with protection are able to nourish and broaden the field of possibilities beyond mere survival. The conclusion is that at La Chim$b a$, the active and fulfilling lives of the immigrants rise from a paradox: the possibility of finding shelter and setting roots (conditions determined by a sense of community and social safety nets), on the one hand; and itinerants and movement (conditions of transcending constraints of local identity and achievement of connectivity), on the other. This paradox assures the preservation of the inhabitants' identities within a multicultural environment while maintaining fluidity of connections with situations beyond the frontiers of the neighborhood, the city and the country.

KEY WORDS | urban culture, urban imagery, immigration.

Recibido el 15 de enero de 2012, aprobado el 31 de mayo de 2012

E-Mail: fmarquez@uahurtado.cl

En este artículo colaboran los coinvestigadores del Fondecyt $n^{\circ}$ 1095083: Ricardo Truffello, geógrafo, Universidad Adolfo Ibánez; Rodolfo Arriagada, arquitecto, magíster en Arquitectura y Urbanismo, Instituto de Estudios Urbanos y Territoriales (IEUT), Pontificia Universidad Católica de Chile (Puc). 


\section{Introducción}

Esta investigación aborda la pregunta por la construcción y génesis de "territorios de frontera" por parte de inmigrantes en La Chimba, al norte del río Mapocho de la ciudad de Santiago. Territorio de fronteras físicas y simbólicas, La Chimba se levanta históricamente como territorio privilegiado para observar las huellas y marcas identitarias que inmigrantes de nuestra ciudad dejan tras de sí en sus desplazamientos y ocupaciones cotidianas al otro lado de la angosta franja del río Mapocho.

Desde evidencias de la historia, la etnografía y georreferenciación se concluye que las referencias territoriales en espacios de frontera y la presencia inmigrante están signadas por la memoria nostálgica del terruño que se dejó atrás, pero también por las prácticas de integración a la ciudad. Se trata de desplazamientos, ocupaciones y prácticas cotidianas que no se orientan solo por la necesidad de sobrevivencia en sentido estricto, sino también por la posibilidad de que el territorio de acogida otorga para producir y significar un modo de habitar otro, distinto al de los residentes originarios, propio.

Sin embargo -y es la tesis central de esta investigación-, sus posibilidades no terminan ahí. Las identidades territoriales de frontera nacen, se crean y se transforman en fuente de poder y de ejercicio ciudadano cuando la configuración de los territorios que las cobijan son capaces de alimentar y ensanchar el campo de lo posible, más allá de la sobrevivencia.

La investigación muestra que la realización de la vita activa (trabajo, acción y obra, en el sentido que le da Arendt, 1983) en estos territorios de frontera depende de la realización de una paradoja: la posibilidad de cobijo y arraigo (condición de comunidad y redes de protección) y, a la vez, de itinerancia y movimiento (condición de translocalidad y redes que articulen a la ciudad y a otras naciones). En este sentido, el carácter de territorio de frontera estaría dado justamente por un doble movimiento: por una parte, el resguardo de sus habitantes en la multiculturalidad; y por otra, la posibilidad e invitación a la conectividad más allá de las fronteras del barrio, de la ciudad y de la nación. Cuando estas condiciones se cumplen -resguardo en el nosotros y conectividad a los otros- la soberanía sobre el propio territorio se asienta, y las sombras de la estigmatización se diluyen.

El objetivo de este artículo es reconstituir de manera comprensiva los procesos temporales y espaciales mediante los cuales, a lo largo de los siglos xx y xxI, olas de migrantes se instalan, ocupan y marcan el territorio de La Chimba (los barrios Recoleta e Independencia), transformándolo en un territorio de frontera; esto es, simultáneamente territorio de cobijo y de apertura a la ciudad y al mundo.

El método es fundamentalmente cualitativo, y se ubica en lo que De Certeau (1999) denominó la socioetnografía, a medio camino entre la sociología y la etnografía, de modo de evitar la discursividad indefinida. La investigación hace dialogar la información objetiva de este territorio de La Chimba para posibilitar la "escenificación de la vida cotidiana" y dar paso a la observación de las acciones y tácticas de los migrantes. 


\section{La Chimba, territorio de frontera}

La ciudad difícilmente puede ser comprendida como el lugar del orden y la coherencia; ella es el lugar, por definición, de la deliberación, de la participación, pero también de la experimentación de la diferencia (Sennet, 2003), de la multiculturalidad (García Canclini, 1995) y la sobreabundancia de sentidos (Augé, 1992). La densidad de interacción, el intercambio y el movimiento son rasgos inherentes a ella, al igual que la presencia de fronteras geográficas y simbólicas como las que conocemos en nuestra ciudad de Santiago.

La Chimba, al norte del río Mapocho, ha sido históricamente nuestro "otro lado" (Figuras 1 y 2). Aun cuando las investigaciones historiográficas enfocadas en los procesos territoriales y urbanos evidencian que desde la canalización del río, a finales del siglo xix, La Chimba y el Mapocho paulatinamente se fueron integrando a la ciudad en lo vial y cultural (Castillo, 2012), lo cierto es que, hasta la actualidad, la angosta franja del río marca la frontera entre la ciudad propia y la ciudad bárbara. Desde su origen, en la Colonia, se instalaron allí, material y simbólicamente, lo que el centro de la ciudad niega: los cementerios, los hospitales, los mercados de abastos y los inmigrantes empobrecidos en busca de mejor fortuna. La Chimba, aldea de indios, ha sido durante cuatro siglos y medio frontera, trastienda, pero también cobijo y lugar de la diversidad. Ella no solo pervive en la segregación simbólica de los muertos al otro lado del río Mapocho, territorio de los esencialmente otros, sino que se perpetúa en poblaciones que en su mixtura mantienen la vitalidad de este territorio (Romero, 1997). Y aun cuando en la actualidad las orillas del río Mapocho evidencian una "apropiación” y urbanización, las evidencias etnográficas indican que, en términos del habitar, al lado norte del río, la "otredad" se persevera en el modo de ocupar, construir, trabajar y ordenar la espacialidad. La Chimba desafía la planificación central y se vuelve emblema de una cierta autarquía. Si el centro de Santiago es la cara de la legalidad y la civilidad, La Chimba es históricamente espalda, contracara y reverso; una ciudadela paralela al otro lado del río.

Geográficamente es el río Mapocho el que fija la frontera, línea divisoria que establece un adentro y un afuera, borde visual hasta donde se llega, pero también desde donde se parte. Borde que fija un territorio de frontera, entendido como el lugar donde se distingue el nosotros de los otros; lugar vago e indeterminado que habla de un estado permanente de transición. Sus habitantes son los que atravesaron esa frontera, los raros, los molestos, los indeseados, los mulatos, los indios, los muertos, los locos, los extranjeros; aquellos que ya cruzaron la frontera o caminan por el precario límite de lo normal (Anzaldúa, 1999). La Chimba se levanta como un territorio físico y simbólico en el que se configuran los referentes identitarios que darán forma a la ciudad de los otros. Esta investigación se ubica justamente en la pregunta por la otredad urbana que representan los migrantes en este territorio de circulación y frontera. 
FIGURA 1 | La Chimba desde el sur, siglo xx

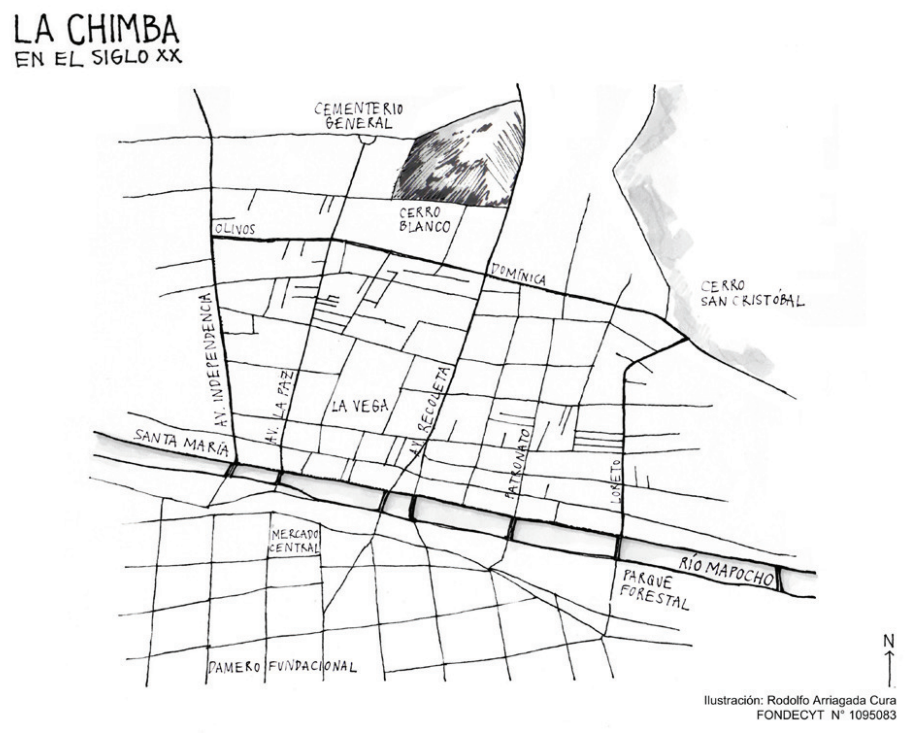

FUENTE CROQUIS DE R. ARRIAGADA, EN PROYECTO FONDECYT NIO95083 (MÁRQUEZ, 2009)

FIgURA 2 La Chimba desde el norte, siglo xx

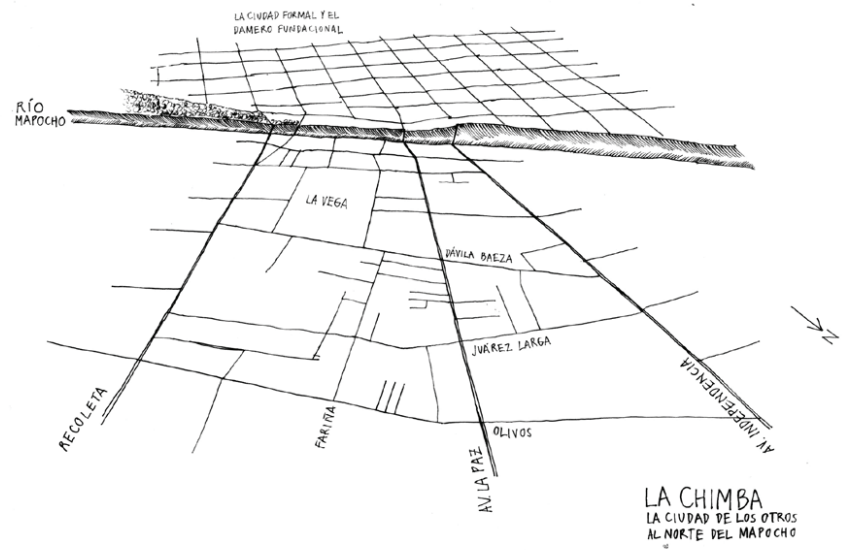

FUENTE CROQUIS DE R. ARRIAGADA, EN PROYECTO FONDECYT NI095083 (MÁRQUEZ, 2009)

\section{Tiempo y espacio del habitar en territorio de frontera}

El territorio de frontera se constituye por definición junto a la figura del extranjero, en los términos de Georg Simmel (1998). Es decir, "el que viene hoy y se queda mañana”, pero siempre el inmigrante en potencia para quien la proximidad y la distancia constituyen dimensiones esenciales y conflictivas en su relación con la ciudad. La movilidad y los contactos ocasionales son dos rasgos constitutivos que marcan la relación del extranjero con el territorio de acogida. En este sentido, la migración es la 
ausencia de vinculación permanente con un punto del espacio, pero su gran potencial es que, en este movimiento, el inmigrante introduce nuevas cualidades y recursos al espacio de acogida. En esta relación ambigua de distancia y proximidad con la ciudad que lo acoge, el extranjero fija su particular y precaria existencia. Y como todo aquel que está de paso, el extranjero puede ser simultáneamente confidente y objeto de sospecha. Su relación con la sociedad es, por definición, un ejercicio problemático.

Porque el inmigrante circula entre espacios jurídicos, territoriales e identitarios que le son ajenos, su figura cuestiona y desnaturaliza los consensos sociales. De allí que leer las historias y prácticas de migrantes en la ciudad requiera necesariamente de la construcción de un paradigma de la movilidad en que se conjuguen las dimensiones problemáticas del movimiento; esto es, la tríada espacio-tiempo-identidad. Toda movilidad social, cultural y económica deja huellas en el espacio y el tiempo; huellas de recorridos, de cambios de residencia, de apropiaciones del suelo, de instalaciones y desinstalaciones, de idas y venidas.

\section{Enfoque metodológico}

Esta investigación se sitúa conceptual y metodológicamente en la experiencia urbana del inmigrante, mediante la observación de los trayectos y prácticas que conforman un territorio de pertenencias translocales en la ciudad. La premisa es que territorios como La Chimba no se experimentan solo como espacios físicos, suma de historias y monumentos, sino como espacios significados que conducen a la permanente reescritura de la experiencia urbana.

\section{Escenarios y prácticas}

Se observan dos aspectos básicos del desempeño espacial y geográfico de la vida cotidiana de estos migrantes: la construcción de escenarios de comportamientos (lugar donde se despliega la práctica); y el desarrollo de prácticas culturales que guían el desplazamiento y construyen principios del habitar en este territorio (Cuadro 1). Ambos -escenarios y prácticas- llenan de contenido geográfico y significativo la vida cotidiana, definiendo lo que denominaremos el hábitat configurativo de nuestra ciudad (De Castro, 1999).

a. Escenarios de comportamientos: Historia migratoria de los grupos étnicos que desde mediados del siglo xx se instalan en este territorio de frontera. Características sociodemográficas de la población migrante a partir de información censal que se construye de la programación de rutinas y codificación de datos de migración por país, cruzada con información de hacinamiento, ocupación laboral y otras variables. Finalmente se caracteriza la traza urbana, arquitectura y emplazamiento de migrantes.

b. Práctica cultural: Prácticas que construyen principios de identificación y guían el desplazamiento por el barrio, la ciudad y el mundo. Imaginarios que hablan de un tiempo y espacio otro (De Castro, 2005). Prácticas y trayectos cotidianos de migrantes en el tiempo y espacio (Giannini, 1992). Redes y vínculos que construyen comunidad y articulan a la ciudad y al mundo. 
CUADRo 1 | Modelo de análisis, dimensiones conceptuales y metodológicas

\begin{tabular}{|c|c|c|c|c|c|c|c|}
\hline & \multirow{2}{*}{\multicolumn{4}{|c|}{$\begin{array}{c}\text { TERRITORIO DE FRONTERA } \\
\text { LA CHIMBA SIGLO XX } \\
\text { HÁBITAT CONFIGURATIVO | } \\
\text { LUGARES SIGNIFICADOS }\end{array}$}} & & & \\
\hline & & & & & & & \\
\hline & \multicolumn{3}{|c|}{ ESCENARIOS DE COMPORTAMIENTO } & \multicolumn{4}{|c|}{ PRÁCTICAS CULTURALES } \\
\hline & $\begin{array}{l}\text { Historia } \\
\text { migratoria }\end{array}$ & $\begin{array}{c}\text { Caracterización } \\
\text { socio- } \\
\text { demográfica }\end{array}$ & Arquitectura & $\begin{array}{c}\text { Trayecto } \\
\text { cotidiano }\end{array}$ & $\begin{array}{l}\text { Marca, } \\
\text { huella }\end{array}$ & $\begin{array}{l}\text { Redes, } \\
\text { vínculos }\end{array}$ & Imaginario \\
\hline $\begin{array}{l}\text { Fuentes } \\
\text { secundarias }\end{array}$ & $\mathrm{x}$ & $\mathrm{x}$ & $\mathrm{x}$ & & & & \\
\hline $\begin{array}{l}\text { Georreferen- } \\
\text { ciación }\end{array}$ & & $\mathrm{x}$ & & & & & \\
\hline Etnografía & & & & $\mathrm{x}$ & $\mathrm{x}$ & $\mathrm{x}$ & $\mathrm{x}$ \\
\hline $\begin{array}{l}\text { Relato de vida, } \\
\text { entrevista }\end{array}$ & & & & $\mathrm{x}$ & & & \\
\hline $\begin{array}{l}\text { Trayecto } \\
\text { comentado }\end{array}$ & & & & $\mathrm{x}$ & $\mathrm{x}$ & $\mathrm{x}$ & \\
\hline Mapa mental & & & & $\mathrm{x}$ & $\mathrm{x}$ & $\mathrm{x}$ & \\
\hline
\end{tabular}

FUENTE ELABORACIÓN PROPIA, FONDECYT Nº I 095083 (MÁRQUEZ, 2009)

A partir del reconocimiento de estos elementos estructurales y experienciales se realiza una socioetnografía, la cual permite establecer -mediante observación, recorridos comentados y mapas cognitivos- la configuración de este habitar de frontera.

\section{Universo del estudio}

El trabajo etnográfico se focalizó en las comunas de Recoleta e Independencia, en el radio que la literatura e historiografía indican como La Chimba: por el sur, avenida Domingo Santa María; al norte, avenida México; al oriente, Calle Loreto; al poniente, avenida Fermín Vivaceta. El universo de informantes recoge la diversidad étnica de La Chimba, por lo que se incorpora también al habitante chileno. Se cuida representar en este universo las diferencias según edad, ocupación laboral, sexo, lugares de residencia y nacionalidad (Cuadro 2).

CUADRO 2 | Universos entrevistados según nacionalidades, 2009-2011

\begin{tabular}{|l|c|}
\hline \multicolumn{1}{|c|}{ HABITANTES DE LA CHIMBA } & $\begin{array}{c}\text { RELATO DE VIDA / RECORRIDOS / } \\
\text { MAPAS IMAGINARIOS }\end{array}$ \\
\hline $\begin{array}{l}\text { Migrantes sin retorno (1948) } \\
\text { Oriente Próximo: Palestino/Libanés/Sirio }\end{array}$ & 20 \\
\hline $\begin{array}{l}\text { Migrantes con retorno (1982) } \\
\text { Asia: Coreano/Chino/Indio }\end{array}$ & 10 \\
\hline $\begin{array}{l}\text { Diásporas (1998-2008) } \\
\text { Latinoamérica: Argentino/Peruano/Ecuatoriano }\end{array}$ & 20 \\
\hline Chilenos & 20 \\
\hline Total & 70 \\
\hline
\end{tabular}

FUENTE ELABORACIÓN PROPIA, FONDECYT Nº I 095083 (MÁRQUEZ, 2009) 


\section{Etapas de la investigación}

a. Escenarios de comportamientos:

i) Sistematización de la información secundaria, archivos históricos siglo xx, georreferenciación censal, mapeo y croquis de traza urbana y arquitectónica;

ii) Etnografía, observación y descripción de prácticas de migrantes, huellas plasmadas en la materialidad (arquitectura, traza urbana), lugares significados y transformados por estas prácticas.

b. Práctica cultural:

i) Relatos de vida y entrevistas en profundidad; trayectoria biográfica de migrantes y habitantes chilenos con objeto de reconstituir sus relatos, imaginarios y tensiones identitarias en los espacios-tiempos de la vida cotidiana y migratoria;

ii) Etnografía de recorridos por la ciudad, el barrio y espacios translocales;

iii) Mapas mentales de recorridos, traslados, viajes y ocupación del espacio. La cartografía simbólica (a diferencia de la cartografía física) -expresada en la construcción de croquis- da cuenta de límites metafóricos e hitos imaginados que indican y unen territorios a una memoria colectiva, a una manera de hacer las cosas. Mediante los croquis se señalan recorridos simbólicos e intersecciones entre los sujetos y su espacio. El relato constituye el soporte de esta cartografía, como sistema de símbolos que da cuenta de los lugares como espacios relacionales, históricos e identitarios (Augé, 1992; De Castro, 2005)

\section{Del escenario y contexto sociohistórico}

\section{Inmigrantes en Chile del siglo XxI}

Las cifras de migración en Chile indican que durante las dos últimas décadas, el país ha pasado de ser un territorio generador de migrantes, a ser crecientemente receptor. Aun así, comparado con la región y el mundo, presenta bajas magnitudes de inmigración. Desde 1940 hasta inicios de los años ochenta, en Chile el fenómeno migratorio se caracterizó por la mayor presencia de personas de origen europeo y la existencia de corrientes árabes y del Extremo Oriente. Solo en las últimas décadas del siglo xx comenzó a predominar, dentro de las corrientes inmigratorias, la población fronteriza sumada a la de países asiáticos, producto del crecimiento económico y la liberalización de la economía desde la década de los ochenta. Con la democracia y la estabilidad política esta tendencia se consolidó.

De acuerdo con el último censo (2002), la población de origen sudamericano constituye un 67,8 por ciento del total de la población extranjera en Chile. Más del 50 por ciento de la inmigración andina llegó al país con posterioridad al año 1996, especialmente en el caso de la población peruana, ecuatoriana y colombiana. Por otra parte, es relevante la gravitación de las mujeres en la composición de la inmigración, donde participan en más del 52 por ciento. Desde el punto de vista etario, la inmigración se caracteriza por ser principalmente laboral, lo que se refleja en el bajo porcentaje de nińos menores de quince ańos. Una característica visible es la población 
económicamente activa, la cual ascendía a 48 por ciento del total de población de inmigrantes en el año 2002. Por otra parte, se han reducido los técnicos y profesionales (de 64 por ciento en 1992 a 45 por ciento en 2002). En cuanto a localización, se observa una importante concentración en la Región Metropolitana, donde reside el 63 por ciento del total de la población inmigrante. Esta corresponde mayormente a lo que se denomina una nueva inmigración, espontánea, procedente de Sudamérica, de origen andino y urbano, femenina y con finalidad laboral (construcción, industria y servicios domésticos) (Instituto Nacional de Estadísticas [INE], 2002). Según estos mismos datos, se puede observar que la magnitud del fenómeno migratorio en el Área Metropolitana de Santiago es de aproximadamente 108.775 inmigrantes extranjeros, equivalente a casi el 2 por ciento de la población total residente en el Gran Santiago.

En los últimos años, un aspecto fundamental de la dinámica de las migraciones en América Latina ha sido el paso de "migraciones sin retorno" (como fueron las primeras oleadas palestinas en nuestro país) a las "migraciones con retorno" (asiáticos, latinoamericanos), donde la relación entre inmigrantes y sus sociedades de origen permanece vigente en cada una de las prácticas que desarrollan en el territorio que los acoge. La presencia de comunidades étnicas en las ciudades y la aparición de prácticas transnacionales entre los inmigrantes parecieran, así, cuestionar el modelo de la asimilación en favor de un modelo que habla de la reactualización de prácticas y formas de vida que trascienden los límites geográficos y políticos de los países. La diversidad étnica y el multiculturalismo emergen con fuerza según los contextos políticos y sociales en que los inmigrantes están insertos. Junto a estas transformaciones, sabemos que nacen nuevos procesos de etnogénesis, los cuales implican que terceras y hasta cuartas generaciones de inmigrantes reactualicen sus vínculos con los territorios de origen, ya no en la perspectiva del retorno, sino que del reencuentro con sus raíces.

\section{Inmigrantes en La Chimba del siglo XXI}

Al otro lado del río Mapocho, entre avenida Independencia y calle Loreto, oleadas de migrantes se han instalado históricamente desde inicios del siglo $\mathrm{xx}$, perseverando así la impronta de territorio mosaico: árabes que llegaron escapando del Imperio Turco Otomano el año 1890; españoles refugiados de la guerra civil a fines de los ańos treinta; palestinos huyendo tras la creación del Estado de Israel en 1948; coreanos en busca de mejores horizontes a comienzos de los ańos ochenta, con la liberalización de la economía chilena; peruanos, ecuatorianos, argentinos escapando de las crisis económicas de sus países durante los años noventa. Lo cierto es que el proceso de inmigración y ocupación de La Chimba por parte de nacionalidades diversas (Figura 3) no se detiene a lo largo de los siglos Xx y XXI, manteniendo así su impronta hasta el día de hoy.

En la decisión de estos inmigrantes de instalarse en La Chimba juegan a favor los bajos precios de los terrenos y las viviendas, pero sobre todo la cercanía a sus iguales (otros inmigrantes) y a los principales servicios de la ciudad. Si bien con la instalación del mercado de La Vega, el año 1895, el carácter comercial y productivo de La Chimba había adquirido especial fuerza, con la llegada de comerciantes y pequeños industriales palestinos, en 1948, ese carácter terminó por consolidarse. En el caso de La Vega, fueron principalmente familias chilenas de chacareros, comerciantes, 
camioneros, jornaleros, las que le dieron vida al sector. Algunos compraron casas en las cercanías, otros hicieron de La Vega su hogar. Años más tarde, los inmigrantes árabes y judíos ocuparon los sectores aledaños a La Vega, como el barrio Patronato y la avenida Independencia. Se hicieron de terrenos y levantaron sus viviendas en los pisos superiores de sus negocios y pequeños galpones industriales, posicionándose como iconos de la incipiente industria y comercio textil en Chile (Agar, 1983).

FIGURA 3 | Inmigrantes por manzana 2002, La Chimba

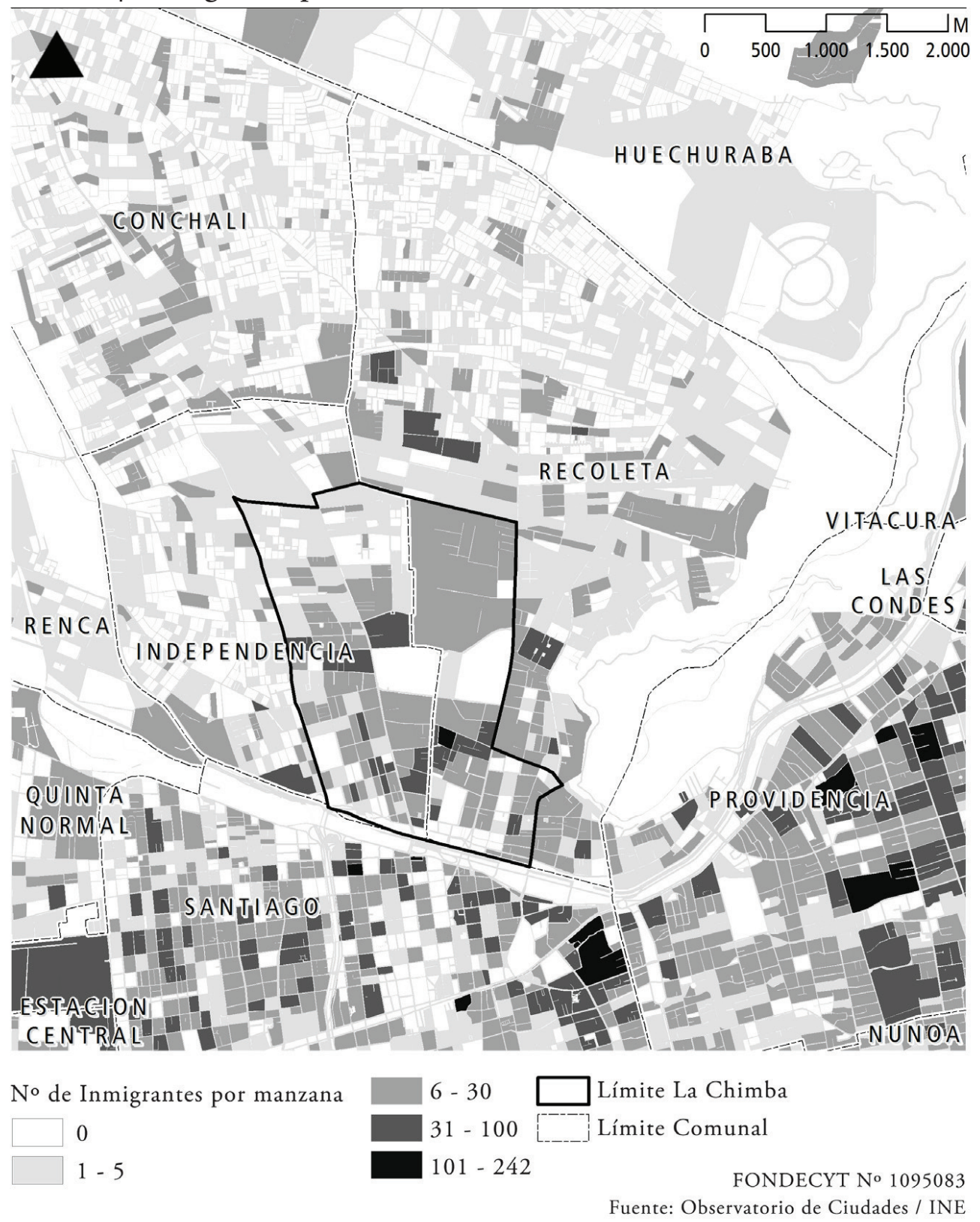

FUENTE ELABORACIÓN DE R. TRUFFELLO, A PARTIR DE OBSERVATORIO DE CIUDADES, PUC. FONDECYT N ${ }^{\circ}$ IO95O83 
En la década de los años ochenta, con la inmigración coreana, Patronato e Independencia se vieron fuertemente afectadas por la política económica orientada a acabar con el modelo de sustitución de importaciones, que, junto con desregular las tarifas aduaneras, desincentivaría el desarrollo de la producción nacional (Salazar \& Pinto, 2002). En el caso de las fábricas de propiedad de árabes, se vieron obligadas a sortear un duro período de crisis, lo que lograron con el arrendamiento de sus locales; en cambio, aquellas que no pudieron reacomodarse al nuevo contexto económico, simplemente quebraron. Fue a partir de los años ochenta que se generó un rápido proceso de densificación del suelo con fines comerciales y residenciales, con la consecuente tugurización de la arquitectura (Figura 4).

FIGURA 4 | Comercio y servicios, La Chimba 2002

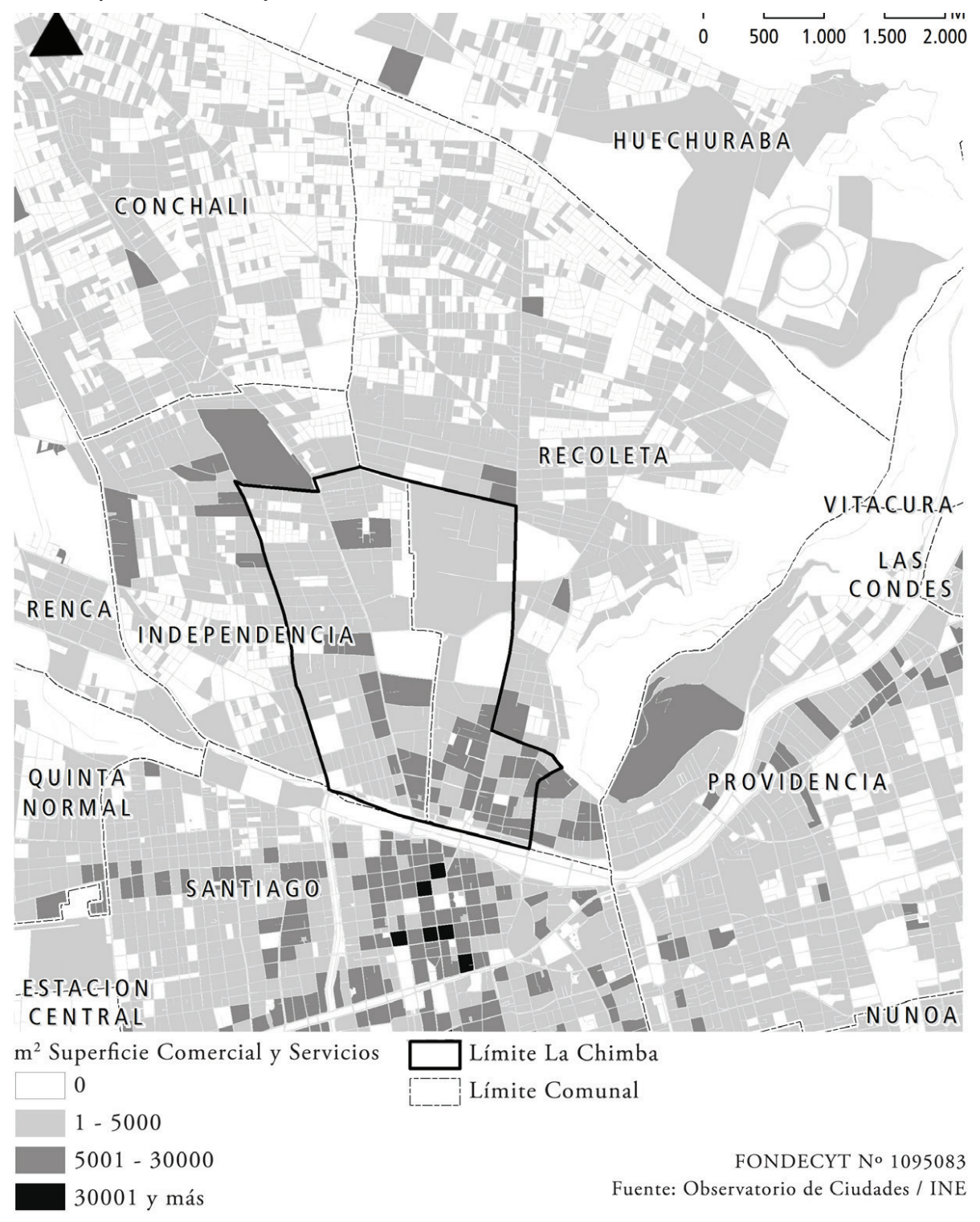

FUENTE ELABORACIÓN DE R. TRUFFELLO, A PARTIR DE OBSERVATORIO DE CIUDADES, PUC. FONDECYT N ${ }^{\circ}$ IO95083 
De forma simultánea al auge del comercio - y en función de aumentar la superficie de ocupación del suelo-, comenzaron a tomar forma los patrones morfológicos que hoy caracterizan a La Chimba (Recoleta e Independencia). El principio funcional de albergar locales comerciales y viviendas fue el que primó en este proceso, superponiéndose a regulaciones de una autoridad central que intentaba planificar el modelo de crecimiento del sector. La actividad laboral y comercial terminó por imponerse y articular esta compleja trama de diversidad etnocultural, creando un espacio de convivencia de actores que transitan cotidianamente por sus calles y tiendas (Figura 5).

FIGURA 5 | Inmigrantes según nacionalidades, predominio por manzana, La Chimba 2002

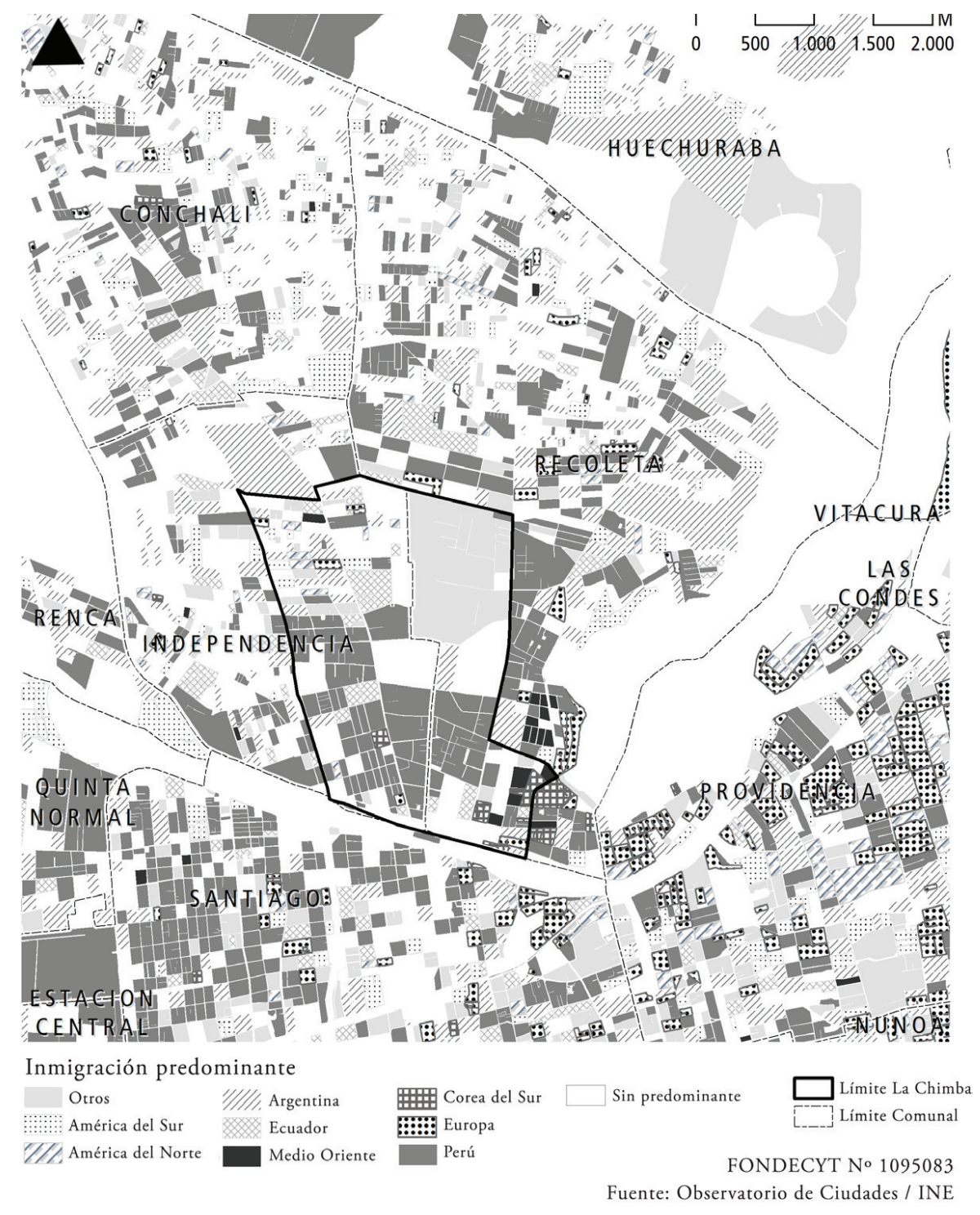

FUENTE ELABORACIÓN DE R. TRUFFELLO, A PARTIR DE OBSERVATORIO DE CIUDADES, PUC.FONDECYT N ${ }^{\circ}$ IO95083 


\section{Prácticas culturales en un escenario de frontera}

\section{Migrar y asentarse en La Chimba}

Las motivaciones que acompańan a las distintas oleadas de inmigrantes no han sido siempre las mismas. Mientras los inmigrantes palestinos llegaron a Chile (años cuarenta) escapando a la crisis política, para "hacer patria" y quedarse junto a sus familias; en el caso de los inmigrantes coreanos (años ochenta) y sudamericanos (años noventa), su migración ha sido caracterizada como diáspora. Vale decir, un tipo de migración motivada por factores económicos, y que se caracteriza por las grandes redes transnacionales entre colonias de un mismo origen etnonacional, así como por la reemigración y la resistencia a la asimilación con la sociedad de acogida (Germaná, Meneses, Valencia, Collatón \& Samamé, 2005; Stefoni, 2011).

Todos ellos, sin embargo -inmigrantes del Oriente Próximo, Asia y Latinoamérica-, llegaron con algún contacto en el país de acogida, Chile. En el caso de aquellos que se establecieron en La Chimba, todos poseían un amigo o pariente que los podía recibir; y todos sabían que en Recoleta e Independencia se encontraba fácilmente residencia y trabajo. "Cuando yo llegué de Palestina, en este barrio había unos seis locales solamente. Esos locales eran de paisanos que en su mayoría llegaron de Palestina. Después de a poco empezaron a llegar más, muchos llegaron de Bolivia. Uno avisa a otro que el barrio está bueno para el comercio y así van llegando. Así se fue poblando este barrio... como todos se conocían entre sî" (Jadue, 60 años, 2007). "Mi barrio [Fariña] lo conozco de allá [Lima], porque un amigo me contó que aquí hay muchos compatriotas. Eso me gusta de aquí..." (José, 33 años, 2011).

Para palestinos, coreanos y peruanos, el patrón de inserción en el lugar es similar: primero es la casa o habitación de un familiar; luego, el arriendo o subarriendo de una habitación propia; finalmente, la compra de una o varias propiedades en el caso palestino y coreano; o arriendo y subdivisión de una vivienda en el caso de peruanos (Figura 6). Esta vivienda será acomodada como habitación en su parte superior o trasera, y como negocio (industria, taller, cocinería, comercio, bodega) en el piso inferior o antesala de la vivienda.

Son los palestinos quienes mejor se han posicionado en este sector, adquiriendo propiedades y paños de suelo tanto en la comuna de Recoleta como en Independencia. En el caso de los inmigrantes coreanos, en un comienzo arriendan locales y viviendas a propietarios árabes, quienes, tras la crisis económica de los ańos ochenta, migraron hacia el sector oriente de la ciudad, pero conservan la propiedad del suelo y edificios. En ańos más recientes, sin embargo, los coreanos también han comenzado a comprar grandes paños de suelo y a invertir.

A partir de los años noventa, tanto chilenos y palestinos como coreanos han incursionado en la remodelación de viviendas que subarriendan por piezas a los inmigrantes latinoamericanos. En el caso de palestinos y chilenos, estas viviendas cumplen con ciertas normas mínimas de constructibilidad. Los coreanos, por su parte, han invertido en grandes galpones sin norma de constructibilidad alguna que, ocultos tras alguna fachada, sirven de habitación a familias de inmigrantes ilegales. Subarrendar es siempre un buen negocio: los ingresos obtenidos serán 
siempre significativamente superiores a lo que se podría obtener por el arriendo de esa misma vivienda a una sola familia ${ }^{1}$. Para los inmigrantes latinoamericanos, la precariedad de sus recursos económicos los obliga a una alta tasa de hacinamiento: "Allá [en Perú] tenemos nuestra casa y todo; acá tenemos que vivir como un animalito enjaulado, porque aparte de chiquito, incómodo, caro, pagas [como si fuera] una pieza de lujo. Allá nos sale barato la pieza; en cambio, acá pagamos lo mismo que un departamento en Lima. Además, cobran caro porque saben que necesitamos vivir cerca del trabajo. Es un abuso" (Violeta, 32 años, 2010).

FIGURA 6 | Habitaciones migrantes peruanos de madera construidas sobre cité de adobe, calle Fariña, 2010

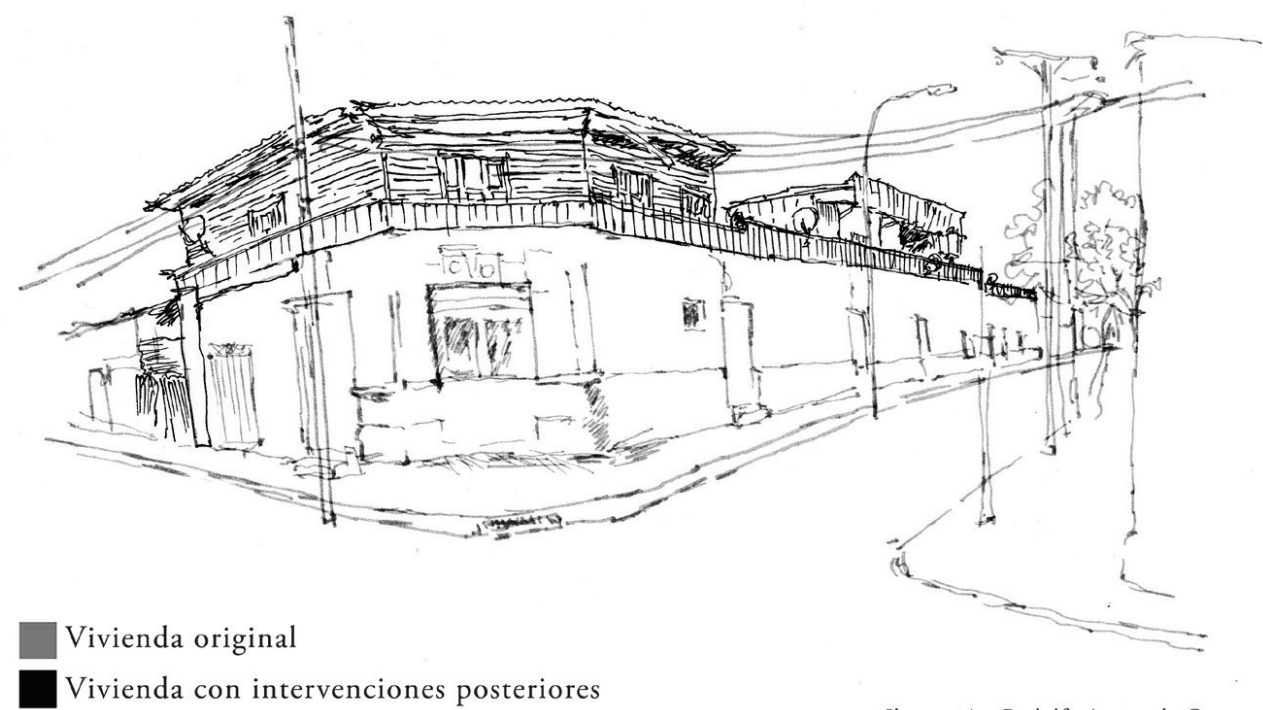

Ilustración: Rodolfo Arriagada Cura

FUENTE CROQUIS DE R. ARRIAGADA, EN PROYECTO FONDECYT N ${ }^{\circ}$ I095083 (MÁRQUEZ, 2009)

\section{Habitar y proxemia}

En La Chimba, la diversidad de sus habitantes informa un cohabitar de la mixtura; no solo en términos de su diversidad étnica, como ya se señalaba, sino también en la diversidad de formas que los vinculan al territorio. Están los que se fueron, antiguos inmigrantes (italianos, alemanes, españoles, palestinos), que lograron una cierta holgura económica y hoy son propietarios de sitios y casonas en La Chimba. Están los que van y vienen, aquellos que a veces duermen en las

1 En un galpón metálico de tres pisos oculto tras una fachada de calle Olivo, propiedad de un coreano, habitan actualmente treinta familias de inmigrantes latinoamericanos ilegales. Cada una paga un arriendo de $\$ 80.000$ mensuales (US\$90) por su habitación de seis metros cuadrados con derecho a cocina, lavadero y baño común. Ello da un total de $\$ 2.400 .000$ mensuales (US\$5.000), precio cinco veces más alto que los arriendos de las casonas del sector. En una vivienda remodelada de calle Fariña, propiedad de un palestino, cada habitación se arrienda en $\$ 90.000$ mensuales (US\$100); allí habitan cinco familias de inmigrantes latinoamericanos, lo que da un total de $\$ 450.000$ mensuales (US\$900) por la vivienda, precio cuatro veces superior al valor de arriendo por una vivienda similar y unifamiliar en el mismo sector. 
calles de La Chimba o en lugares como la Casa de Acogida o los espacios de La Vega. Están los que se quedaron, antiguos residentes chilenos e inmigrantes, clase trabajadora y pobre, habitantes de los deteriorados cuartos redondos, cités y casas pareadas. Son los antiguos vecinos vinculados a La Vega, al comercio y prestación de servicios diversos. Ancianos que en las tardes de sol sacan sus sillas a la vereda para conversar o se resguardan en alguno de los bares de parroquianos a compartir las penas y novedades del sector. Están los recién llegados, de países latinoamericanos, peruanos fundamentalmente, que hoy ocupan cuartos de cité y conventillos. Peruanos que conviven entre sí, pero que mantienen vínculos laborales, de vecindad y comensalía con sus vecinos chilenos.

En términos de la proxemia (Hall, 1979), son ciertamente los palestinos quienes más marcan su presencia en el territorio. Apostados en los umbrales de sus negocios o en las cafeterías del barrio, conversan y ríen con quien quiera darse el tiempo. Pero no solo signan de sociabilidad el barrio, también de ciudadanía transnacional. La Unión General de Estudiantes Palestinos, la Catedral Ortodoxa y la Cámara de Comercio de Patronato, constituyen actores que dan vida y presencia política al sector, ya sea a través de embanderar y cubrir de luto las calles y locales del barrio, o bien organizando y reivindicando los derechos del pequeño comerciante de este otro lado de la ciudad.

Muy diferente es la presencia de los coreanos en este territorio. Apostados tras sus vitrinas y mesones, rara vez se dejan ver. Aunque un penetrante aroma emerge siempre de sus locales -anunciando que allí se habita y se cocina-, su escasa "competencia lingüística" en el castellano actúa como trinchera desde donde cualquier contacto bicultural se vuelve imposible, a pesar de su evidente presencia económica en el sector.

En el caso de los inmigrantes latinoamericanos, de migración más reciente y con menos recursos, la proxemia comparte una cierta paradoja. Si bien para ellos el lenguaje actúa como "vehículo de la cultura", y su buen manejo les permite actualizar y redefinir las identidades de manera dialogante, facilitando una cierta competencia bicultural, la precariedad de su habitabilidad y los altos niveles de hacinamiento dificultan una proxemia de la visibilidad en el territorio. Apertrechados en espacios fuertemente tugurizados de pasajes o cités transformados en laberintos, los peruanos mantienen una visibilidad efímera. Es decir, si para el palestino su lugar es la puerta de la tienda, el café de la esquina, y para el coreano, la trastienda del mesón de su local, en el caso del peruano su lugar es la calle y el movimiento constante. El peruano nunca se asienta plenamente. En La Chimba su presencia es fugacidad, tanto en el habitar como en su trabajo y celebración. Incentivados por organizaciones católicas, las calles de La Chimba y el centro de la ciudad -plaza de Armas, iglesia Catedral y paseo Ahumada- se transforman en coloridos escenarios de comparsas y festejos religiosos para los provenientes de países andinos. Es la fiesta del Señor de los Milagros y Santa Rosa de Lima, en el caso de inmigrantes peruanos; de la Virgen de Copacabana para los bolivianos. Sin trabajo estable, sin residencia clara, y profundamente creyentes, los peruanos parecieran estar siempre de paso. $Y$ sin embargo, es justamente en este transitar que ellos construyen sus redes y contactos como un tejido que los amarra al lugar y a sus habitantes. 
Entre uno y otro migrante, el vecino chileno de La Chimba también marca su presencia en el habitar. Apostado en la puerta de su local, de su tienda o de su casa, el chileno mira y murmulla una conversación ininterrumpida con quien quiera escucharle. Esta conversación lenta, pausada, que se instala en las veredas como un rumor, amarra los hechos y aconteceres del barrio. Y como relato, a veces quejumbroso, fija ciertos principios de identidad de La Chimba. Relato que recuerda que, allí, la mixtura étnica siempre existió, pero que la presencia de latinoamericanos nunca había sido tan grande. Relato que advierte, a veces al pasar pero de manera clara, que para habitar en el barrio se debe guardar un cierto respeto a los principios básicos de la convivialidad: limpieza y trabajo. Relato que, como amalgama, entrega ciertas directrices y principios de lo que sería el buen habitar.

Es esta tensión entre la proxemia y los relatos lo que justamente otorga a $\mathrm{La}$ Chimba su carácter de territorio nunca acabado, siempre en movimiento; entre unos y otros, el barrio adquiere la posibilidad de tierra fronteriza, siempre en disputa.

\section{El trabajo y la higiene como principios del habitar}

Para todos los habitantes, los que permanecieron y los que se fueron, uno de los aspectos más atractivos de La Chimba es la diversidad de fuentes laborales que ofrece al recién llegado. En este territorio, la experiencia de integración y cobijo está amarrada a una alteridad construida sobre la relación de trabajo. En otros términos, el trabajo es una experiencia estructurante del habitar. La etnografía informa de la relevancia que adquiere, en este territorio multicultural, la presencia de la actividad productiva y comercial vinculada al mercado de La Vega, al comercio y servicios de Patronato, Recoleta e Independencia.

La observación etnográfica indica, sin embargo, que son los habitantes y trabajadores chilenos, clase media envejecida, pero habituada históricamente a la convivencia con inmigrantes, quienes afianzan y reactualizan los códigos del trabajo y el esfuerzo al interior del territorio. Las evidencias empíricas permiten levantar la hipótesis de que son estos habitantes chilenos los que otorgan al barrio su condición de continuidad, pero, sobre todo, de cobijo y protección. Es en ellos donde residen las claves de la integración, una integración urbana que se mueve en una compleja red de vínculos y reciprocidades, y donde los códigos de "la decencia" (Martínez y Palacios, 1995) operan como ética que ordena las relaciones de vecindad, sociabilidad, trabajo y urbanidad. En este código no es la honradez, la temperancia o el buen nombre de familia lo que se releva. En este territorio del movimiento, tránsito y precariedad, el trabajo y la higiene (limpieza) son el garante de un ethos territorial siempre frágil; y, por ende, constituyen principios normativos intransables de convivencia y conveniencia (De Certeau, 1999). Son la amalgama que resguarda hacia adentro (cobijo en el territorio) y amarra el afuera (conectividad al resto de la ciudad). Porque "después de Dios está La Vega" (refrán que todos comparten), romper con este ethos no puede sino significar la condena a la perdición y el desvarío. Cuando la fuente de trabajo se pierde y la suciedad gana lugar, chilenos y migrantes emprenden rumbo hacia otros territorios. Parte significativa de la partida de familias chilenas a otros barrios y comunas está asociada al fin de su fuente de trabajo en el mercado de La Vega; pero también al deterioro y suciedad de sus calles. 
La importancia del esfuerzo y el trabajo, así como el valor de la limpieza personal y territorial, son parte de las conversaciones cotidianas de los chilenos que comparten relaciones de vecindad con los inmigrantes latinoamericanos. El valor de la temperancia solo adquiere vigencia si su transgresión atenta contra el principio del trabajo. En el bar de parroquianos, frecuentado principal o únicamente por chilenos, todos podrán reconocerse como alcohólicos, pero nadie podría ser catalogado de flojo o reticente al trabajo. Todos trabajan, y así lo atestigua el delantal de cargador, la "yegua" o el carro que se deja apostado en la puerta, los sacos de alimento, y las herramientas que reposan al costado de la barra donde se comparte una cerveza o un pipeño.

Así también ocurre con el principio de la higiene. Los vecinos chilenos de La Chimba se saben pobres, pero siempre limpios y ordenados. Y de allí, los reclamos y las conversaciones que una y otra vez advierten, a quien quiera escuchar, del valor de la limpieza en el buen vivir (barrer, desinfectar, limpiar, pintar, vacunar, ordenar). "En las noches, viernes en la noche, sábado en la noche, [los peruanos] hacen comida en las calles. Es una falta de higiene, porque ponen la parrilla en la calle, venden en la calle, pasan el dinero... iqué higiene puede haber!” (Berta, 60 ańos). A modo de silenciosa sanción, los chilenos evitan las calles sucias y estas van quedando vacías. Es una seńal que, sin embargo, los migrantes reconocen no como señal de xenofobia, sino como principio del buen vivir:

Para qué te voy a mentir, este barrio es mejor, este barrio, por ejemplo, La Vega, en comparación con mi país. Nosotros le llamamos la Parada. Es igual, se vende todo por mayor y esas cosas, pero allá es mucho más peligroso. Allá hay demasiados rateros; acá también hay, pero no tanto como allá... Allá te roban, en cambio acá como que te conocen y te respetan. Si hay [ladrones], son pocos... Aparte que es más limpio que allá; si acá veo que recogen la basura, allá es cochino; la basura toda amontonada, no hay quién recoja la basura, van dando vueltas, allá no la recogen... Esa parte de acá me gusta, porque es más organizada, es distinto. Aparte que la gente es bien amable; acá hay buena gente, pero hay algunos que te tienen un poco de cólera. (Isabel, 2010)

La multifuncionalidad de la vivienda -residencia y acopio- expresa bien este principio de un ethos centrado en el trabajo como garante del habitar de frontera. La coexistencia de la habitación y el trabajo es un principio que pareciera transversal a sus habitantes, chilenos o migrantes (Figuras 7 y 8 ). La presencia generalizada de la vivienda-bodega, donde la familia extendida se constituye y organiza en función del trabajo, es un buen ejemplo del principio estructurante que lo laboral tiene en la constitución del habitar de frontera. El patrón ocupacional de La Chimba, por parte de los inmigrantes, en especial sudamericanos pobres, no difiere mucho del patrón que rige entre los chilenos, en especial aquellos vinculados al mercado de La Vega. La vivienda en La Chimba tiene siempre un carácter polifuncional. 
FIGURA 7 | Casa bodega familia chilena, 2010
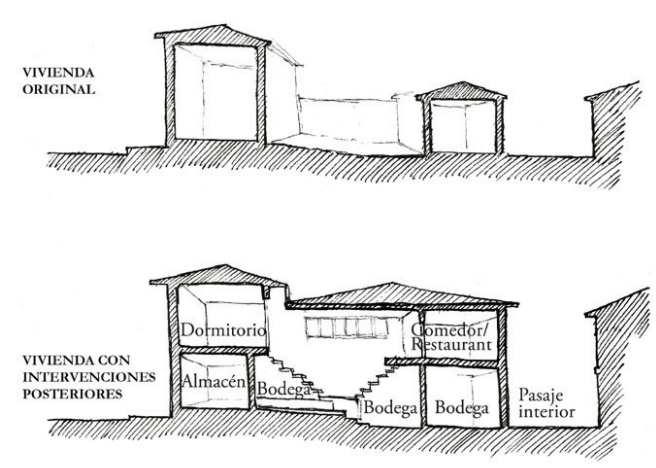

Ilustración: Rodolfo Arriagada Cura
FIGURA 8 | Casa bodega familia peruana, 2010

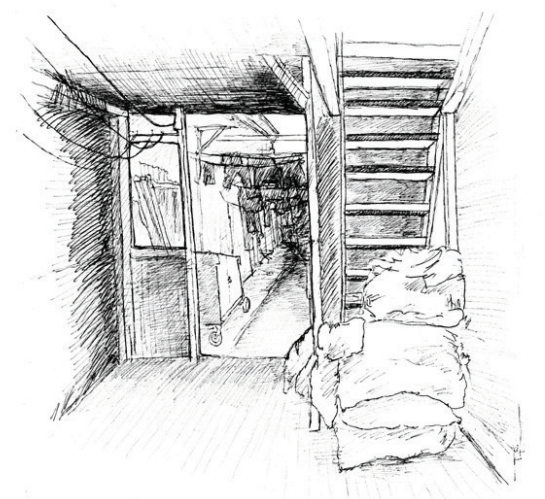

Ilustración: Rodolfo Arriagada Cura

FUENTE CROQUIS DE R. ARRIAGADA, EN PROYECTO FONDECYT N ${ }^{\circ}$ IO95083 (MÁRQUEZ, 2009)

La Figura 7 corresponde a la vivienda-bodega de una familia chilena que por generaciones ha trabajado en la producción y venta de hortalizas en el mercado de La Vega. El corte de la vivienda muestra las remodelaciones que ha sufrido para ajustarla a las necesidades de bodegaje. A la estructura original de adobe se le han incorporado subdivisiones que posibilitan compatibilizar las necesidades del hogar (segundo piso) con aquellas propias al desempeño en el comercio de hortalizas (primer piso). La Figura 8 corresponde a una vivienda subdividida en habitaciones donde viven familias peruanas. A la entrada y junto a la escalera, donde guardan sus instrumentos de trabajo, se observa un carro para la venta, sacos de productos y otros utensilios.

Así como palestinos y coreanos instalan sus negocios de manera visible y formal, en el caso de los inmigrantes peruanos la estrategia es la invisibilidad, la informalidad y la fugacidad de sus instalaciones. Faltos de capital, al empleo doméstico y el trabajo en la construcción se suma la venta de alimentos u objetos varios como solución a la obtención de ingresos. Cada pieza, cada vivienda y cada local opera simultáneamente como residencia, guardería de niños, cocinería y bodega para carros e implementos.

\section{Cobijo y conectividad}

Decíamos que La Chimba ha operado históricamente como espacio de cobijo y acogida. En ella el migrante no solo encuentra a otros iguales, sino también trabajo y redes sociales desde donde iniciar una estrategia de integración en la ciudad. Las redes, a menudo situadas territorialmente, amarran a la sociedad de acogida, pero también actualizan los vínculos con la sociedad de origen, posibilitando la experiencia de la translocalidad.

La Chimba, en este sentido, ofrece una riqueza y diversidad en equipamiento y servicios que posibilita a quien llega, permanecer y operar en el territorio sin verse obligado a salir de él. La condición de cobijo y conectividad constituye el gran recurso del territorio de La Chimba, aspecto que pareciera haber permanecido y haberse consolidado a lo largo de la historia de las oleadas migratorias. Un cobijo que otorga el encuentro con otros migrantes en situación de vida similar; y una 
conectividad que asegura la ubicación privilegiada que otorga el equipamiento del lugar y la cercanía al centro de la ciudad. Cobijo y conectividad que se construyen de la mano de una cierta autonomía relativa que le otorga al sector su historia e identidad de enclave migratorio y distrito industrial/comercial. Son estos lugares y sus equipamientos los que finalmente amarran las prácticas en el espacio.

El barrio ha cambiado, según se desprende del relato de los chilenos e inmigrantes más antiguos; hoy pareciera más violento, aunque igualmente pobre y desordenado. Sin embargo, para los más antiguos, los hitos de pertenencia y arraigo, en especial aquellos que hablan de la infancia, siguen estando allí. Nostalgias que en el ejercicio cotidiano de recorrer el barrio y saludar a los vecinos se reactualiza una y otra vez. Así también sucede para los inmigrantes más recientes. La Chimba, dice una entrevistada chilena, "parece un pueblo chico, donde todos se conocen, pero también todos se enojan bien fácil”.

Los recorridos hablan de movimientos y tránsitos en todas las direcciones: están aquellos que se mueven por el propio barrio como en un laberinto de pasajes secretos, y conocen cada uno de sus pasadizos; están aquellos que sin cruzar el río se mueven a lo largo de este, hacia el oriente y el poniente, siempre entre iguales y con iguales (trabajadores precarios y ancianos); y están aquellos que cruzan el río, ya sea para hacerse un lugar (vendedores informales y vagabundos) o integrarse al mercado laboral de los servicios (empleadas domésticas y obreros de la construcción). Para unos y otros, los que cruzan o no el río, La Chimba ofrece siempre caminos, más o menos riesgosos, para conectarse a otros lugares, otros espacios, otros recursos. La Chimba es, por definición, siempre posibilidad.

El croquis siguiente (Figura 9) muestra justamente esta capacidad del territorio de acoger y resolver los afanes cotidianos de sus habitantes. Como muchos que habitan en La Chimba, los trabajadores informales evitan cruzar el río. Salvo para descansar en los parques de la orilla sur, o participar junto a otros migrantes de una celebración religiosa, o desempeñarse en un trabajo formal (empleada doméstica o maestro de la construcción), los trabajadores informales rara vez cruzan el río. Solo los inmigrantes más valientes, los "guerreros", como les llaman, osan atravesar los puentes que los llevan al centro de la ciudad. Aun cuando en el centro histórico de la ciudad las ganancias pueden ser mayores, ellos preferirán quedarse en La Chimba y persistir en hacer de este territorio su centro de operación y trabajo. La Chimba, en su carácter de distrito comercial y productivo, alienta la creación de fuentes de trabajo y retiene en su interior a los más vulnerables. Ciertamente los puentes amarran ambas orillas, pero en este tránsito nadie está seguro de regresar. 
FIgURA 9 | Recorrido cotidiano de habitante peruana. Barrio Fariña, La Chimba, 2010

\section{LA CHIMBA \\ EN EL SIGLOXX}

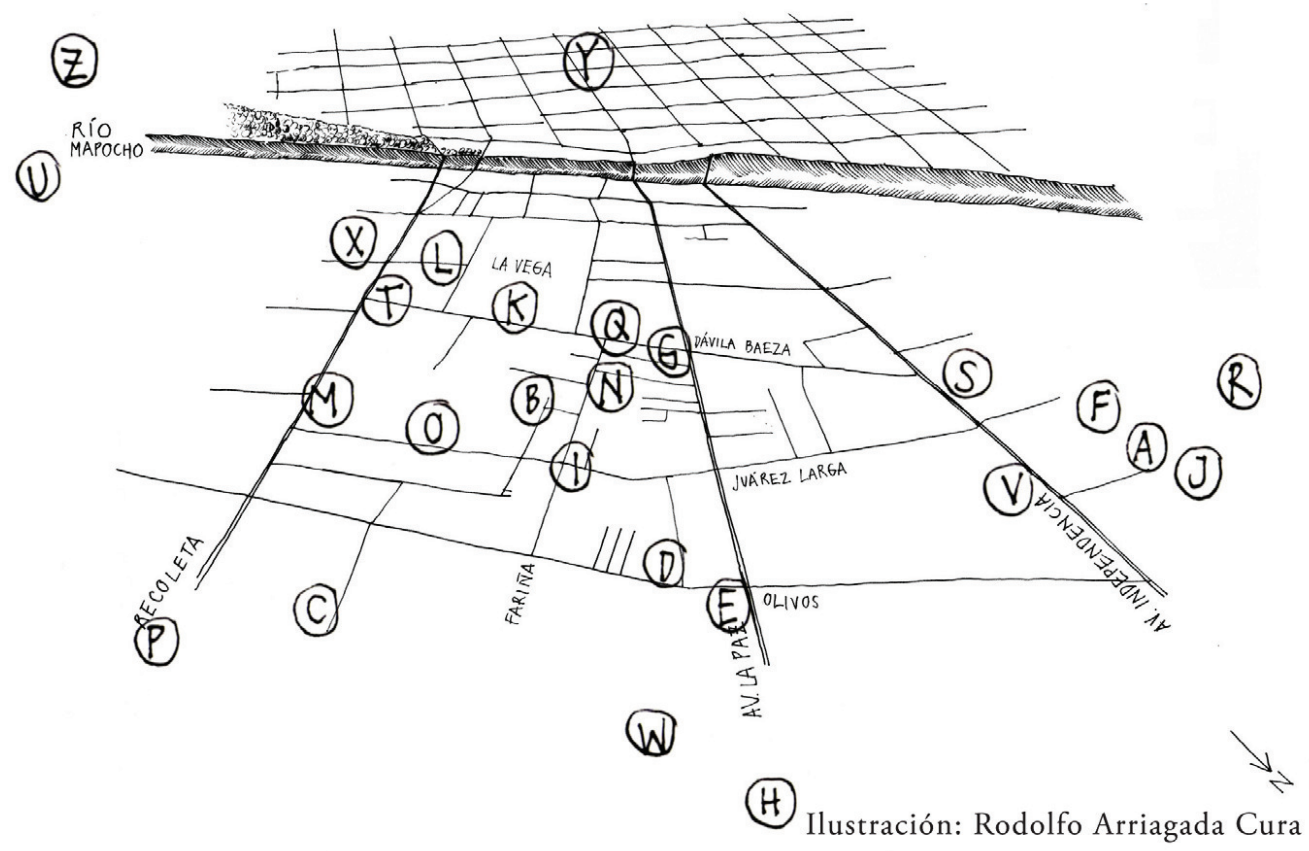

Figura 9: Rosy, 35 años, peruana, reside en Chile hace ocho años en La Chimba, casada, 4 hijos. Lugares de residencia: a) Maruri, pieza subarrendada cuando llega a Chile; b) Pasaje Irizarri, subarrienda pieza a chileno; c) Rengifo, subarrienda piezas en cité a palestino. Lugares de familia y amistad: d) Juárez Corta, vive hermana con su familia; e) Av. La Paz c/Olivos, vive cuńado con su familia; f) Maruri, vive tía, primo y primas; g) Dávila, amigos; h) Parque los Reyes, paseo familiar y amigos; i) Juárez Larga, locutorio, llama todas las semanas a su familia; j) Maruri, restaurant donde cuidan y alimentan a sus hijos después de la escuela. Lugares de abastecimiento y servicios: $\mathrm{k}$ ) La Vega Chica, compra alimento; 1) La Vega Central, Lastra con Rengifo, mercadería para su carro de venta de alimento; m) Av. Recoleta, colegio de sus hijos; n) Fariña, cité, compra pan amasado a vecina; o) Juárez Larga, ayuda a cocinería informal de conocida peruana, p) Recoleta, consultorio, atendió su último embarazo; q) Dávila, comisaría, permisos de residencia y trámites legales; r) Fundación Las Rosas, ayudan con ropa y alimento; s) Av. Independencia, local, envía remesas hacia Perú. Lugares de trabajo: t) Lastra, instala su carro de comida; u) Pío Nono, instala carro de comida; v) Av. Independencia, kiosco donde trabaja su marido; w) Calle Charlín, trabaja en cuidado de anciana chilena. Lugares de oración: x) Iglesia La Recoleta; y) Catedral de Santiago, celebración fiesta del Señor de los Milagros; z) Bustamante, Parroquia Italiana, asiste talleres de costura y ayuda, procesión Santa Rosa de Lima.

FUENTE ETNOGRAFía DE LA AUTORA; CROQUIS DE R. ARRIAGADA, EN PROYECTO FONDECYT N ${ }^{\circ}$ IO95083 (MÁRQUEZ, 2009)

\section{Imaginarios del habitar translocal}

Aunque el carácter de translocalidad se actualiza una y otra vez en las prácticas cotidianas de los inmigrantes -a través del envío de remesas, llamadas telefónicas, acogida de familiares, idas y venidas al país de origen-, es en los mapas imaginarios donde el carácter de la translocalidad adquiere un sentido más complejo y menos asible. Tal como se observa en los croquis siguientes (Figuras 10 y 11), para los 
migrantes, el propio barrio, cargado de nostalgia y afecto, está en el país de origen. Los dibujos se detienen con cuidado en el mundo de lo doméstico, de la sociabilidad y de su hábitat. En los mapas de presente, la representación de La Chimba se centra fundamentalmente en las posibilidades laborales que este territorio les abre; en el orden y la disposición de las viviendas, de las bodegas y de la propia habitación. La representación del hábitat no pareciera tener más significado que el de proveer trabajo. Salvo en los mapas elaborados por jóvenes inmigrantes, donde la centralidad de la representación está puesta en los espacios de sociabilidad (calle, plazas, parque); para sus padres, La Chimba representa la ciudadela que ofrece las oportunidades de trabajo a quienes la habitan. Para unos y otros, el río está siempre presente, como la frontera que los separa del resto de la ciudad.

\section{FIGURA 10 | Mapa imaginario inmigrante:} barrio en Lima, Perú, 2010

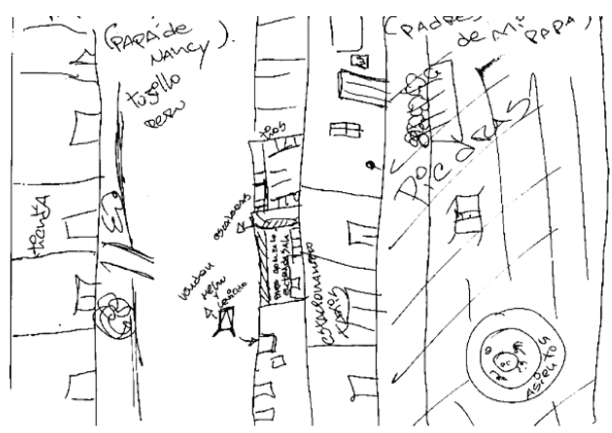

FIGURA 11 | Mapa imaginario inmigrante: barrio en Lima, Perú, 2010

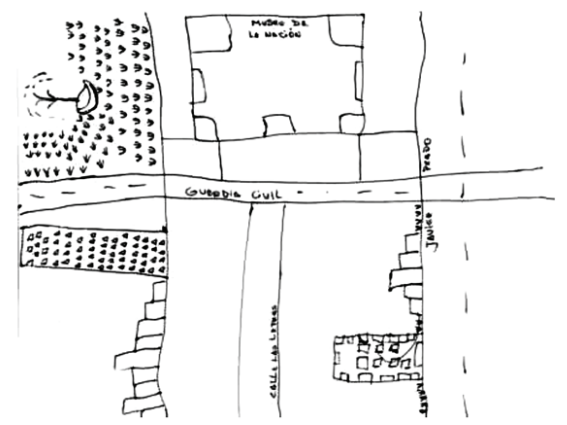

FUENTE CROQUIS DE S. GRANADOS, EN PROYECTO FONDECYT N ${ }^{\circ}$ IO95083 (MÁRQUEZ, 2009)

En la Figura 10, Susy, peruana, 17 años, dibuja el barrio de Lima, Perú. Se destacan dos casas, las de su abuelo materno (papito Gonzalo) y de la abuela materna (Dona), a quienes visitó el año pasado. En la Figura 11, Lily, peruana, 28 años, destaca la elegancia de su barrio, "allá donde yo vivía en Perú, era lindo, como Las Condes, es como un barrio cuico que le llaman aquí".

Las Figuras 12 y 13 corresponden a croquis de inmigrantes peruanas; ambas representan La Chimba, lugar donde residen, como un territorio centrado en la producción, el almacenaje y el comercio. Es el carácter de distrito comercial y productivo el que se destaca, dejando perdido en ese espacio el propio lugar de residencia. 
FIGURA 12 | Mapa imaginario inmigrante: La Chimba, 2010

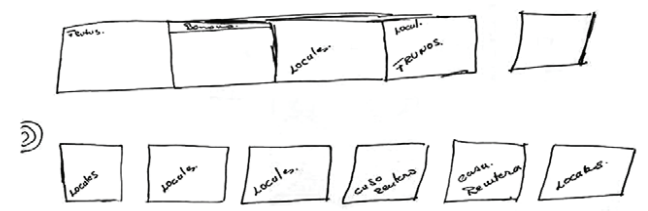

FIGURA 13 | Mapa imaginario inmigrante: La Chimba, 2010

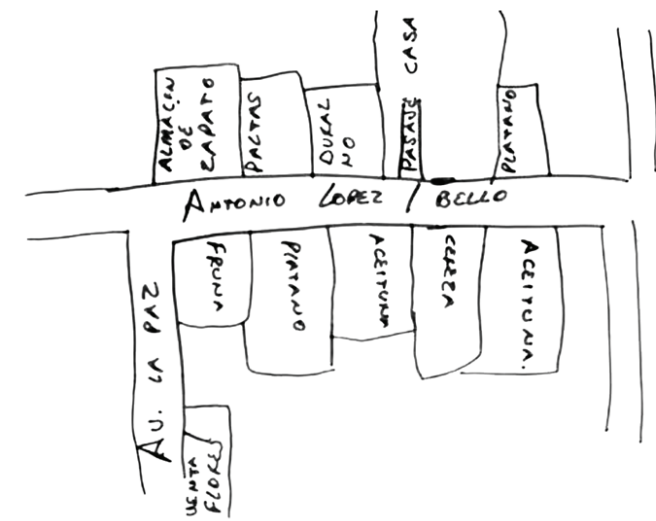

FUENTE CROQUIS DE F. BERRIOS, EN PROYECTO FONDECYT N ${ }^{\circ}$ IO95083 (MÁRQUEZ, 2009)

\section{Conclusiones}

\section{Territorio de frontera}

En La Chimba, la condición de umbral -territorio de resguardo y conectividadofrece la posibilidad de un habitar movedizo y flexible (Delgado, 2007). En el habitar de La Chimba, asentamiento siempre precario, nada se amarra definitivamente, ni los cuerpos, ni las formas, ni las arquitecturas, ni los arraigos. Como una ciudadela campamento, en La Chimba no se requiere credencial de ciudadanía para asentar el propio cuerpo y los pocos enseres. Como en todo asentamiento de frontera, la maleabilidad y capacidad de metamorfosis de los lugares, del cité, de la vivienda, del bar, de la calle, la caracterizan. Esta maleabilidad de los espacios para acoger, esconder o proteger a sus habitantes habla de un habitar donde la zonificación propia de la modernidad y de la planificación urbana pareciera no tener cabida. Estamos frente a un territorio donde los principios del desorden (Jacobs, 1993) toman fuerza y sentido; un lugar de una plasticidad que poco responde a la lógica estructuradora y segregadora de una ciudad como Santiago. El río como frontera protege, y se encarga de recluir al otro lado, en la otra banda.

Es esa misma precariedad del habitar la que posibilita la elaboración y expresión de una afectividad colectiva, difusa, no siempre verbalizada, pero efectiva. La dimensión afectiva aparece en escena de una manera imprecisa -no necesariamente funcional- en cada una de las prácticas de los habitantes en el territorio. En esta imprecisión, La Chimba surge espacialmente en su dimensión matrística (Maturana, 1990), femenina; espacio de acogida, útero. Es posibilidad siempre abierta al recién llegado, al que necesita reposo, alimento, aun cuando pronto partirá: migrantes, vagabundos y vagabundas, cesantes, bohemios, curaitos, paisanos, putas, parroquianos, huachos. Porque todos caben y todos circulan, la xenofobia no puede tener lugar: el "otro" es siempre una posibilidad. El estigma -entendido como la marca que fija y marca- pierde toda su razón de ser. Pervive 
una afectividad que toma forma en gestos cotidianos, y cuya contracara a menudo es también la incertidumbre y el miedo al estallido, a la violencia, a un desorden propio de un espacio que es, por definición, frontera y trastienda de una ciudad metrópoli cuya cuadratura y orden habla de control.

Podríamos decir que esta es la ciudad de los códigos difusos y los manuales rotos, espacio de los principios de inteligibilidad implícita (Reguillo \& Godoy, 2005). A este lado de la frontera, los códigos y manuales de urbanidad de la ciudad propia pierden su poder para organizar el sentido y la práctica del lugar. En La Chimba, más que manuales - principios preestablecidos-, los códigos del habitar se develan de manera difusa y siempre problemática. Aquí, en este territorio de frontera, los códigos del habitar -trabajo e higiene- se actualizan una y otra vez, mirando a los otros, rozando cuerpos, transitando por los espacios y lugares. La Chimba es territorio donde las certezas y principios del habitar se tejen de la mano del vínculo y la alteridad entre diferentes.

\section{Frontera y translocalidad}

Señalábamos al inicio de este artículo que la realización de la vita activa (Arendt, 1983) en estos territorios de frontera depende de la actualización de una paradoja: cobijo (comunidad y redes de protección) y conectividad (translocalidad y redes que articulan a la ciudad y otras naciones). En este sentido, el carácter de este territorio de frontera que es La Chimba estaría dado justamente por la posibilidad de asegurar el resguardo de los migrantes en la diversidad, pero a la vez facilitar la conectividad más allá de sus fronteras. Es la aparente contradicción que nos muestra como, junto a los procesos crecientes de deslocalización y migración, se crean procesos de relocalización en nuestras ciudades, que anuncian un imaginario y un habitar más soberano y ciudadano (Reguillo \& Godoy, 2005; Low \& Lawence, 2001; Ramírez \& Aguilar, 2006).

El dinamismo que imponen estas prácticas translocales a los territorios contribuye al desdibujamiento de las narrativas que naturalizan las historias locales y barriales. Y en este proceso, el problema ya no es el pluralismo cultural, la diversidad de identidades en sí, sino la tensión entre diversidades que transitan y una ciudad segregada que no las reconoce en sus diferencias (Appadurai, 1996). Los territorios de frontera, como La Chimba, territorios porosos y diversos en sus identidades, a menudo ponen en tensión los proyectos homogeneizadores y dominantes del Estado-nación y de nuestra planificación urbana. Comprender los sentidos en disputa en nuestra ciudad frente al surgimiento y la diversificación de estas lealtades no nacionales y no territoriales, es un desafío a la investigación urbana. La Chimba nos advierte que las diferencias culturales de la otra banda no son solo respuesta a la exclusión desde el centro, sino más bien una evidencia de las limitaciones de la ciudad propia, para acoger y representar al conjunto. 


\section{Referencias bibliográficas}

Agar, L. (1983). El comportamiento urbano de los migrantes árabes en Chile. EURE [en línea], 9(27), 73-84. Recuperado de http://bit.ly/1dLNyh6

Anzaldúa, G. (1999). Borderlands - La Frontera. The new mestiza. San Francisco, Ca: Aunt Lute Books.

Appadurai, A. (1996). Modernity at large: Cultural dimensions of globalization. Minneapolis, MN: University of Minnesota Press.

Arendt, H. (1983 [1961]),.La condition de l'homme moderne. Paris: Calmann-Lévy.

Augé, M. (1992). Non-Lieux. Introduction a une anthropologie de la surmodernité. Paris: Seuil.

Castillo, S. (2012). El río Mapocho y sus riberas: Espacio público e intervención urbana en Santiago de Chile (1885-1918). Tesis para optar al doctorado en Arquitectura y Estudios Urbanos; Facultad de Arquitectura, Diseńo y Estudios Urbanos, Pontificia Universidad Católica de Chile.

De Castro, C. (1999). Mapas cognitivos. Qué son y cómo explorarlos. Scripta Nova: Revista electrónica de geografía y ciencias sociales, 33. Recuperado de http://www.ub.es/geocrit/ sn-33.htm

De Certeau, M. (1999). La invención de lo cotidiano: artes de hacer. México: Universidad Iberoamericana.

Delgado, M. (2007). Sociedades movedizas. Pasos hacia una antropología de la calle. Barcelona: Anagrama.

García Canclini, N. (1995). Consumidores y ciudadanos. México, D.F.: Fondo de Cultura Económica.

Germaná, C., Meneses, M., Valencia, I., Collatón, R. \& Samamé, D. (2005). La migración internacional. El caso peruano. Lima: Fondo Editorial de la Facultad de Ciencias Sociales, Universidad Nacional Mayor de San Marcos (UNMSM).

Giannini, H. (1982; 1992). La réflexion quotidienne: vers une archéologie de l'expérience. Paris: Alinea.

Geertz, C. (1973). La interpretación de las culturas. México, D.F.: Gedisa.

Hall, E. (1979). Au-delà de la culture. Paris: Seuil, coll. Essais, Points.

Instituto Nacional de Estadísticas (INE), Chile. (2002). Resultados generales Censo 2002. Santiago, Chile: INE. Recuperado de http://bit.ly/a4DfsH. También Censo 2002. Sintesis de resultados. En http://www.ine.cl/cd2002/sintesiscensal.pdf

Jacobs, J. (1993). The death and life of great American cities. New York: Modern Library.

Low, S. \& Lawrence, D. (Eds.). (2001). The anthropology of space and place. Locating culture. London: Blackwell Publishing.

Márquez, F. (2009). La ciudad de los otros. Inmigrantes en territorios de frontera: La Chimba en el siglo xx. Proyecto Fondecyt n ${ }^{\circ} 1095083$ (2009-2012). Santiago de Chile.

Márquez, F. (2012). Habitar la ciudad bárbara: La Chimba del siglo xxi. Revista 180. Arquitectura y Diseño, 16(29), 6-9. Recuperado de http://www.revista180.udp.cl/ ediciones/29/revista_180_29.pdf

Martínez, J. \& Palacios, M. (1995). Informe sobre la decencia. Santiago: Ediciones SUR.

Maturana, H. (1990). Biología de la cognición y epistemiología. Temuco: Ed. Universidad de la Frontera.

Ramírez, P. \& Aguilar, M. (2006). Pensar y habitar la ciudad. México, D.F.: Anthropos. 
Reguillo, R. \& Godoy, M. (2005). Ciudades translocales: espacios, flujo, representación. Perspectivas desde las Américas. Tlaquepaque, Jalisco: Instituto Tecnológico y de Estudios Superiores de Occidente (ITESo), Universidad Jesuita de Guadalajara.

Romero, L. A. (1997). ¿Que hacer con los pobres? Elite y sectores populares en Santiago de Chile 1840-1895., Buenos Aires: Ed. Sudamericana.

Salazar, G. \& Pinto, J. (2002). Historia contemporánea de Chile. Tomos I, II, III. Santiago: LOM.

Simmel, G. (1998 [1908]). Las grandes urbes y la vida del espíritu. En El individuo y la libertad, Ensayos de crítica de la cultura (pp. 246-261). Barcelona: Ed. Península.

Sennet, R. (2003) El respeto. Sobre la dignidad del hombre en un mundo de desigualdad. Barcelona: Anagrama.

Stefoni, C. (2011). Mujeres inmigrantes en Chile. ¿Mano de obra o trabajadoras con derechos? Santiago: Ediciones Universidad Alberto Hurtado. 